\title{
Adolfo de Francisco Zea. Homenaje a un gran hombre y un gran médico
}

\author{
Adolfo de Francisco Zea. A tribute to a great man and a great physician \\ Jorge León-Galindo* \\ Servicio de Cardiología, Fundación Santa Fe de Bogotá, Bogotá, Colombia \\ Editor Emérito de la Revista Colombiana de Cardiología
}

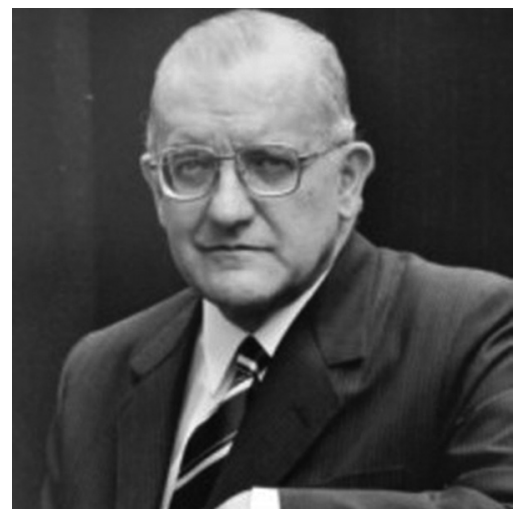

El Dr. Adolfo de Francisco Zea partió dejando en las páginas de la historia una huella indeleble. No solamente sus compañeros de vida profesional y académica nos sentimos anonadados y tristes por su partida, sino que también el país entero le extrañará.

Quiero expresar mi agradecimiento a mi amigo el Dr. Guillermo Sánchez Medina, psiquiatra y psicoanalista excelso, quien completó datos importantes sobre el curriculum vitae del Dr. De Francisco. El Dr. Sánchez Medina y el Dr. De Francisco Zea fueron amigos muy cercanos desde su juventud, y su amistad recorrió sus vidas a lo largo de los años. El Dr. Sánchez Medina comenta sobre las reuniones realizadas en forma periódica en su casa, los sábados a las 11 de la mañana, las cuales se prolongaban hasta las 15:30 si el Dr. De Francisco se quedaba para almorzar, y si no lo hacía, terminaban a la 1:30. Eran reuniones en las que trataban asuntos intelectuales, históricos, científicos y académicos, aunque también asuntos personales. Traigo este recuerdo revelador de la personalidad de los actores, la disciplina y la necesidad de intercambiar conceptos para así aclarar sus ideas.

El Dr. De Francisco Zea fue uno de esos personajes que es difícil olvidar. Le recuerdo por su gallardía innata, su amabilidad permanente, siempre respetuoso con las ideas de su interlocutor, aunque también agudo y preciso en sus conceptos. Elegante y educado en su vestir y comportamiento, y a su vez sencillo en el trato.

En este punto quiero narrar el hecho anecdótico durante el cual conocí a Adolfo, allá en el siglo pasado, a finales de la década de 1950, periodo «pre-marcapasos cardiaco". Mi padre, el Dr. Darío León Rey, llamó a su amigo el Dr. Adolfo de Francisco, quien recién había llegado de su entrenamiento en el exterior, para que evaluara a mi tío bisabuelo Eduardo Venegas Andrade, octogenario que presentaba una bradicardia grave con episodios a diario de pérdida de conocimiento. Conocí a Adolfo, y lo recuerdo claramente,

\section{Correspondencia:}

*Jorge León-Galindo

E-mail: jleongalindo@gmail.com licencia CC BY-NC-ND (http://creativecommons.org/licenses/by-nc-nd/4.0/)
Disponible en internet: 29-07-2021

Rev Colomb Cardiol. 2021;28(3):203-206
www.rccardiologia.com

Rev Colomb Cardiol. 2021;28(3):203-206
www.rccardiologia.com
Fecha de recepción: 16-06-2021

Fecha de aceptación: 17-06-2021 DOI: 10.24875/RCCAR.M21000047 tículo open access bajo la 
gateando «en cuatro patas» buscando un tubo metálico en un baño de la casa para conectar el cable del polo a tierra para disminuir la interferencia en el trazado del electrocardiograma tomado en un electrocardiógrafo, creo que era un Sanbom con caja de madera. Recuerdo que le encontró un bloqueo auriculoventricular completo y lo que presentaba el paciente correspondía a lo descrito por los doctores irlandeses William Stokes y Robert Adams. En ese entonces yo tenía alrededor de 13 años y mi hermano Darío tenía 16. El Dr. De Francisco y nuestro padre nos enseñaron cómo realizar las maniobras de reanimación para aplicarlas cada vez que nuestro tío Eduardo perdiera el conocimiento. Con mi hermano Darío nos alternábamos en turnos para estar al lado de su cama. Desafortunadamente, mi tío Eduardo falleció por esta causa, pues no alcanzó a vivir la época del marcapasos, que llegó unos años más tarde. Este fue mi primer encuentro con la cardiología.

El recuerdo del Dr. De Francisco perdurará en la memoria de la medicina, y especialmente en el campo de la cardiología, por sus valiosos aportes. Recuerdo con el Ing. Jorge Reynolds cuando le hicimos una entrevista en su casa para conseguir datos para el libro que estábamos elaborando sobre la Historia de la Cardiología en Colombia. En esa ocasión tuve la oportunidad de conocer a sus queridas mascotas, Lolita y Salvador, dos gatos preciosos que no se despegaron de su lado durante toda la entrevista. Recordaban que al regresar al país tanto el Dr. De Francisco como el Ing. Reynolds se vincularon a la Fundación A. Shaio, alrededor de 1957. Ellos, junto con el Dr. Rubén Salazar, eran los que calibraban el electrocardiógrafo y la máquina de circulación extracorpórea para las cirugías cardiacas. Cuenta el Dr. Reynolds que calibrar esa máquina no era labor de poca monta, pues duraban dos días haciéndolo antes de la cirugía. El Dr. De Francisco participó en investigaciones sobre el efecto de las alturas en el sistema cardiovascular y respiratorio, junto con los Dres. Enrique Urdaneta, Gustavo Restrepo y Rubén Salazar. El Dr. De Francisco fue quien montó un cuarto con especificaciones para realizar y determinar el metabolismo basal, y medir el consumo de oxígeno en un paciente.

A continuación, trataré de traer lo más relevante del extenso y valioso curriculum vitae del Dr. De Francisco. Se graduó de bachiller del Liceo Cervantes, en Bogotá. Terminó los estudios de medicina en la Universidad Nacional, en noviembre de 1952, con la tesis La comunicación interauricular. En esta Universidad obtuvo la Matrícula de Honor en 1948, el Grado de Honor de la
Facultad de Medicina en 1950 y la Medalla del Internado en 1952, en el Hospital San Juan de Dios. Luego hizo su internado en Medicina Interna en la New York University, en el Bellevue Hospital de Nueva York (julio de 1953 a julio de 1954). Fue médico residente en el Bellevue Hospital, Cornell University, Nueva York (1954 a 1955). Fue becario de la American Heart Association como Research Fellow, Cornell University. También fue becario en el Instituto Nacional de Cardiología de México, Ciudad de México, (julio de 1955 a noviembre de 1956). Ejerció como médico asistente del British Heart Hospital y becario del British Council, Londres (1958). Fue médico asistente en hemodinamia y angiografía en el Hospital Boucicaut, y becario de la Alianza Francesa, Paris (1964). Realizó la especialidad en Psicoanálisis en el Instituto Colombiano de Psicoanálisis, título de Analista (1969 a 1973).

Fue Jefe de Clínica Médica en el Hospital San Juan de Dios (1957-1958), profesor auxiliar de Medicina Interna, Universidad Javeriana (1960-1963); perteneció al grupo de fundadores de la Fundación Abood Shaio (1957-1968); miembro del Departamento de Medicina Interna en el Hospital de La Samaritana (1960); jefe del Departamento de Medicina Interna de la Universidad Nacional (1965-1967); presidente de la Sociedad Colombiana de Medicina (1963-1965); presidente del IV Congreso Colombiano de Cardiología, Bogotá (agosto de 1963), presidente de la Asociación Colombiana de Medicina Interna (1966-1968); presidente del VII Congreso Nacional de la Asociación Colombiana de Medicina Interna (Bogotá, 1967); miembro del Comité Médico del Hospital San Juan de Dios (1965-1967); miembro del Personal Docente y de la Junta Administradora del Hospital Neuropsiquiátrico de Mujeres (1965-1967), de la cual fue presidente; miembro asociado de la Academia Nacional de Medicina (1966), nombrado como Miembro de Número (1973) y Miembro Honorario en el año 2011.

Fue director general del Instituto Colombiano de Seguros Sociales (1968-1970); delegado de Colombia en la Reunión sobre Salud y Bienestar Social en las Naciones Unidas, Nueva York (septiembre 1968); miembro del Comité de Expertos en Salud, Seguridad Social y Educación Médica, Washington (agosto 1969); Conferencia José María Lombana Barreneche de la Asociación Colombiana de Medicina Interna (agosto 1972) y de la Cuarta Conferencia Alfonso Uribe Uribe, El hombre frente a la muerte, Universidad Nacional (1991).

También fue Miembro de Número de la Academia Colombiana de Historia (2002), de la Academia de la Lengua (2008) y de la Academia de Historia de Bogotá, 
Miembro Correspondiente de la Academia de Medicina de Medellín (1974) y Miembro Emérito de la Sociedad Colombiana de Cardiología (2000); Miembro Honorario de la Sociedad Colombiana de Psiquiatría (1970) y miembro de seis sociedades científicas nacionales más. Perteneció a sociedades extranjeras, como la Royal Society of Medicine, la Sociedad de Cardiología de México, la International Cardiovascular Society, la Asociación Latinoamericana de Academias Nacionales de Medicina, la Societé Internacionale de Medicine Interne (Suiza), la Real Academia de la Historia y la Real Academia de la Lengua (España).

Fue receptor de numerosas distinciones y condecoraciones. Con razón, el Dr. Sánchez Medica considera que son pocos los colombianos que hayan recibido tal número de condecoraciones y distinciones como las que le fueron otorgadas al Dr. De Francisco Zea. Para iniciar mencionaré las más relevantes, como la Orden de Boyacá, Gran Cruz (1970), la Orden Civil Antonio Nariño, la Cruz de Esmeralda, categoría Precursor (1976), la Medalla de Fisiología, Universidad Nacional (1946), la Medalla del Internado U. Nacional (1952), la Orden Carlos Echeverri Herrera del Instituto Colombiano de los Seguros Sociales (2000), la Gran Cruz de Oro de la Beneficencia de Cundinamarca (1976) y la Cruz de Oro de la Fundación Hospital San Carlos (1990). Fue honrado con una Placa de Plata del Instituto Colombiano de Seguros Sociales, como Director (1971), y con la Placa de Plata del Hospital San Juan de Dios, como Director (1985). Recibió la distinción de Maestro en Medicina Interna y Cardiología del Departamento de Medicina Interna de la Fundación Santa Fe de Bogotá (2008).

Fue autor de numerosos artículos científicos e históricos, y de libros como El Dr. José Félix Merizalde y la medicina a comienzos del siglo XIX en Santa Fe de Bogotá, El Humanismo y la Medicina, Luís Zea Uribe, su vida y su época, La locura de Don Quijote y Sobre Ideas y Muerte. Fue coautor del Gran Libro de Colombia y de Páginas de su historia; libro del bicentenario. Recibió por la Academia Nacional de Medicina el Bastón de Oro en Honor a una Vida.

El Dr. De Francisco fue un intelectual inquieto. Exploró campos en el terreno de la medicina interna, en especial en cardiología, pero esa inquietud intelectual no se limitó al campo científico sino que alcanzó también al histórico, investigando lo ocurrido en el tiempo pasado en los ámbitos médico, social y político de nuestro país, y su relación con el mundo analizando lo ocurrido y su influencia con el presente. Historiador, escritor insigne y letrado reconocido por las Academias de la Lengua y de la Historia, y profundo conocedor de la salud pública en nuestro país, a la cual aportó importante contribución. Inquieto por la situación hospitalaria, logró grandes avances en su desarrollo, y uno de sus mayores retos y preocupaciones fue el mejoramiento de la seguridad social de los colombianos.

No quiero dejar de mencionar y recordar con gran placer, y también con gran nostalgia, los desayunos los días jueves en la cafetería de la Fundación Santa Fe de Bogotá, luego de la reunión semanal de la Sección de Cardiología, cuando disfrutamos las discusiones entre los Dres. Gustavo Restrepo, Enrique Urdaneta y Adolfo de Francisco sobre hechos históricos, sobre lo ocurrido en las batallas de las guerras europeas, como en la Segunda Guerra Mundial cuando argumentaban sobre por qué en la batalla de Dunkerque, en 1940, cerca de 340,000 soldados ingleses y franceses fueron rescatados por los aliados del ejército alemán de una muerte evidente. Discutían sobre quién fue el que dio la orden de suspender el ataque alemán para aniquilar a estos miles de soldados, si la orden fue dada por Hitler directamente o por el general Von Rundstedt, o si tuvo que ver en esta decisión la influencia política del primer ministro inglés Winston Churchill. También las conversaciones se extendían a otros campos históricos, tales como los «asuntos de faldas» en las cortes europeas o la enfermedad que padecía determinado monarca o reina, y de cuál fue la causa de su muerte. Sobre Catalina la Grande de Rusia, discutían si su amante Grigori Orlov, quien depuso y mandó matar a Pedro III el 17 de julio de 1762, lo hizo o no por orden de Catalina para tomar el trono. Tales argumentaciones históricas se extendían también al campo médico, y en especial las relacionadas con la realeza europea, como si la dolencia del trasero del Rey Sol Luis XIV de Francia tuvo que ver con decisiones políticas tomadas por el rey, debido a que el pobre paciente tenía grandes dificultades en poner sus posaderas en una silla, y sobre todo en una silla de montar a caballo, que era el medio de transporte en esa época; luego de innumerables tratamientos, fue el cirujano Félix de Tassy quien operó y alivió el problema hemorroidal y su fístula. Comentaban que el rey, en agradecimiento, le pagó generosamente en dinero y también con una finca en Normandía, y le concedió un título nobiliario. La curación del rey fue motivo de regocijo del pueblo francés, y Jean Baptiste Lully compuso un himno exaltando la sanación de Luis XIV, Grand Dieu sauve le Roi, que más tarde inspiró a Handel para componer el himno de Inglaterra, God save the Queen o God save the King. 
En días pasados tuve el gusto de hablar con su hija Diana, a quien al recordar a su padre le generó una reacción de jovialidad y de orgullo, y en su cara se reflejó una sonrisa. Esta reacción irradia la remembranza de la personalidad de Adolfo, alegre, positivo y fino en sus comentarios. "Para mostrarte cómo era mi padre - me comentó Diana - te contaré un episodio que pasó un par de meses atrás de su muerte. Estando en el Servicio de Urgencias de la Fundación Santa Fe, día congestionado con pacientes con COVID-19 y con otras causas médicas, mi padre esperaba pacientemente sentado a que le atendieran debido a una dolencia que tenía. Al pasar el tiempo, cansado y molesto por los síntomas que le aquejaban, quiso llamar la atención para ser atendido. Sacó su pipa, también emblema de su personalidad, la encendió y luego de una profunda inspiración expelió una gran bocanada de humo, disparando las alarmas electrónicas y también del personal médico y de enfermería, quienes inmediatamente asistieron donde se encontraba y alguien le preguntó muy respetuosamente por qué fumaba dentro del hospital, a lo que respondió: "solamente quería dejarles saber que estoy esperando a que me atiendan"."

El Dr. De Francisco fue parte de una familia tradicional bogotana. Su padre, el Dr. Jorge de Francisco Cabo, médico especializado en inmunología y dedicado al laboratorio clínico; su madre, Doña Elvira Zea Hernández. Él fue el menor de tres hijos. Se casó con
Doña Gloria Serpa Flórez, mujer con gran inquietud intelectual, con Grado en Filosofía y Letras de la Universidad de los Andes. Tuvieron cinco hijos; Gloria, la mayor, vive en Kansas, Estados Unidos, está casada con un médico urólogo y tienen dos hijos, uno de ellos médico; luego sigue Martha, ingeniera de sonido, tal vez una de las primeras mujeres que estudiaron ingeniería de sonido en el mundo, que vive en Montreal, Canadá, y trabaja en la Universidad de McGill; la tercera es Diana, matemática, que ha trabajado en la enseñanza de esta ciencia por 40 años en el Colegio Andino, también es cantante y pertenece a la Coral Santa Lucía; luego Andrés, médico especialista en medicina tropical y social, que ha trabajado con la Organización Mundial de la Salud y la Organización Panamericana de la Salud; y Adolfo es el menor, dedicado al servicio social, a la ayuda de los necesitados y también a diferentes empresas en su organización y supervisión. El Dr. De Francisco se casó en segundas nupcias con Doña Alicia Jungüito (q.e.p.d), quien le acompañó en las últimas décadas de su vida.

El Dr. De Francisco partió y dejó una huella indeleble en sus pacientes, para quienes no solo fue su médico, sino también su amigo y su guía. En sus colegas permanecerá el recuerdo de su amabilidad, caballerosidad y compañerismo. Sus amigos le recordaremos con admiración y respeto, y sus hijos y nietos transmitirán su gran legado a sus descendientes. Su ejemplo perdurará en el tiempo. 